
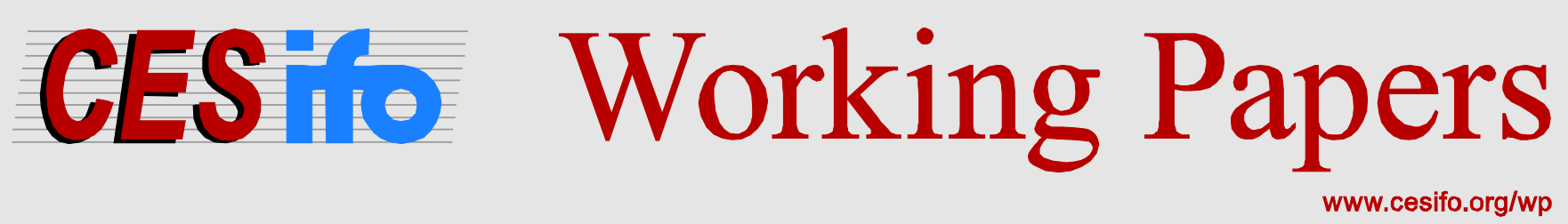

\title{
The Search for Abatement Technologies in the Alberta Oil Sands
}

\author{
Alain-Désiré Nimubona \\ Ujjayant Chakravorty \\ Andrew Leach
}

\author{
CESIFO WORKING PAPER NO. 4781 \\ CATEGORY 9: RESOURCE AND ENVIRONMENT ECONOMICS \\ MAY 2014
}

An electronic version of the paper may be downloaded

- from the SSRN website:

- from the RePEc website:

- from the CESifo website:

WWW.SSRN.com

www.RePEc.org

www.CESifo-group.org/wp

\section{CESifo}




\title{
The Search for Abatement Technologies in the Alberta Oil Sands
}

\begin{abstract}
We develop a three-stage model of abatement technology search, adoption, and deployment. Using this model, which draws on search theory tools more frequently used in labour and monetary economics, we compare market-based and command-and-control pollution control instruments with respect to the incentives each provides for abatement technology search and adoption, expected emissions reductions, and expected compliance costs. We motivate our work by examining firm-level decisions in the oil sands region of Alberta, Canada, where firms are developing new abatement technologies to reduce fluid tailings associated with mining operations. We show that the polluting firm always has more incentives to search for and adopt a more efficient abatement technology under either an emissions tax or a tradeable permit system than under an equivalently stringent emissions standard. We also show that while expected incentives for innovation are comparable under emissions taxes and tradeable permit regimes, the likelihood for total future compliance costs to be reduced after an increase in the stringency of environmental policy - the so-called Porter hypothesis - is higher with a tradeable permit regime.
\end{abstract}

JEL-Code: Q550, Q580, H230, D830.

Keywords: abatement technology, search, prices versus quantities, oil sands, Porter hypothesis.

\author{
Alain-Désiré Nimubona \\ Department of Economics \\ University of Waterloo \& CIRANO \\ Waterloo, Ontario N2L 3G1, Canada \\ animubona@uwaterloo.ca
}

\author{
Ujjayant Chakravorty \\ Department of Economics \\ Tufts University \\ 02155 Medford MA, USA \\ ujjayant.chakravorty@tufts.edu
}

\author{
Andrew Leach* \\ Alberta School of Business \\ University of Alberta \& CIRANO \\ Edmonton, AB, Canada T6G 2R6 \\ andrew.leach@ualberta.ca
}

*corresponding author 


\section{Introduction}

Environmental technology adoption decisions are sticky. Changes in a firm's environmental technology will generally involve significant fixed costs, potential uncertainty about the complementarity between the new technology and existing production processes, and uncertainty with regard to the eventual performance of the technology in terms of delivering compliance with regulations. These frictions imply different outcomes from changes in regulatory stringency.

A particular example of this type are the oil sands of Alberta, Canada, where new environmental regulation and changing public sentiment regarding their environmental footprint has forced firms to take action in developing new abatement technologies to reduce fluid tailings associated with mining operations - changes which have seen individual firms invest billions of dollars. While there are relatively few (5) firms involved in oil sands mining, and the extraction operations are largely similar, operators have chosen vastly different solutions to meet new regulations put in place to limit tailings production. ${ }^{1}$ In this paper, we show that in an environment characterized by significant uncertainty with respect to abatement technology performance and large costs of technology assessment and adoption, the choice of environmental policy mechanism will have significant impacts not present under perfect information and frictionless adoption. We develop these results using search models, commonly used in labor economics but not widely applied to environmental problems. ${ }^{2}$ We show that the significant ex post variation in technology choices as well as collective efforts to reduce technology uncertainties seen in the Alberta oil sands are consistent with a search model of abatement technology.

We develop and solve a stylized, three-stage model of abatement technology search, adoption, and emission abatement. Our model involves one polluting firm and a continuum of external abatement technologies that differ according to their cost efficiency. We examine firms' decisions to search for and potentially adopt and deploy new technology in response to environmental regulation which can take the form of an emissions tax, tradable emis-

$\overline{1}$ For extensive details on specific technologies and firms involved, see the Canadian Oil Sands Innovation Alliance Tailings Technology Roadmap Project, 2014.

2 For a survey of the use of search-theoretical models in labor economics, see Rogerson et al. (2005). 
sions permits, or an emissions standard. We find that the improvement relative to current technology required to adopt a new abatement technology is higher under the emissions standard than under the emission tax and the permit system - this results from the fact that changes in total pollution control costs drive both the technology search and adoption decisions while marginal costs drive abatement decisions. As such, emissions pricing policies with lower marginal costs may drive more innovation and lower future emissions than higher marginal cost policies implemented by regulatory instruments.

We then compare search, adoption and abatement decisions under different types of pollution control instruments based on the likelihood that each will lead to lower ex post total compliance costs under more stringent policy - the strong form of the Porter hypothesis. Our model of search and adoption frictions implies that both ex ante and ex post dispersion in technology across otherwise identical firms is consistent with a rational expectations equilibrium. We characterize both the conditions under which a result consistent with the Porter hypothesis is feasible and under which it would be the expected outcome of a policy change. We cannot explicitly rank emissions standards and emissions tax systems in terms of their likelihood of supporting the Porter Hypothesis, but we do find that a tradeable permit system is more likely to support the Porter hypothesis than a comparable emissions tax. Both emissions-pricing policies always dominate the emissions standard in terms of motivating search and adoption, but we cannot rank them in terms of the potential for admitting lower ex post compliance cost.

Our work builds on the seminal contribution of Weitzman (1974) and on a number of other important papers which analyze the implications of the regulator's uncertainty about abatement costs on the ranking of policy instruments according to polluting firms' incentives to engage in innovative activities. ${ }^{3}$ Milliman and Prince (1989) and Jung et al. (1996) find that auctioned permits provide the most incentives to adopt an improved technology and that taxes provide more incentives than free tradeable permits, which in turn dominate emissions standards. Fischer et al. (2003) and Jaffe et al. (2003) suggest that there is no unique ranking of these alternative policy instruments. Requate and Unold (2003), considering equilibrium aspects and the timing of environmental regulation, highlight the fact that all polluting firms will not necessary adopt new abatement technologies. They do not find any difference between auctioned and grandfathered permits,

$\overline{3}$ See Jaffe et al. (2002) and Requate (2005) for excellent surveys of this literature. 
and suggest that the ranking of taxes and permits is ambiguous. We find similar results, including the implied ex post deviation in adoption decisions. Other studies focus, instead, on damage and target uncertainty (Fischer and Sterner, 2012) and on more complex cases of simultaneous and correlated uncertainty over abatement costs and damages (Stavins, 1996). In this paper, we focus on the uncertainty over future abatement costs, but we make a different argument by focusing on the fact that polluting firms themselves may not know with certainty the cost of new abatement technologies before they adopt them. We open the black box of abatement expenditures by introducing abatement cost uncertainty as well as search and adoption costs to the polluting firm's decision.

Our contribution to the literature is three-fold. First, we complement the literature on the ranking of environmental policy instruments based on polluting firms' incentives to deploy improved abatement technologies by characterizing their search and adoption decisions under alternative policy instruments. We highlight the importance of search and adoption costs and uncertainty over the performance of available abatement technologies in the analysis of abatement technology adoption decisions. To the best of our knowledge, the underlying search frictions have not previously been recognized. While Biglaiser and Horowitz (1995) have made a somewhat similar attempt, they focus on the analysis of incentives to adopt new abatement technologies under emissions taxes and do not compare alternative policy instruments. Unlike the case of cost reduction through endogenous learning-by-doing explored in Bramoullé and Olson (2005), we focus on how environmental regulation induces a polluting firm to incur search and adoption costs to secure an improved technology. We consider a continuum of abatement technologies, but abstract from the presence of many polluting firms as in Perino and Requate (2012). ${ }^{4}$ Second, we contribute to the literature on the Porter Hypothesis (Porter and van der Linde, 1995; Ambec et al., 2013) by formalizing an answer to the question of why firms, which are assumed to be profit maximizing, might require the presence of stringent regulations in order to adopt profit-increasing technologies. We suggest that strict environmental regulations are needed because of the presence of high search and adoption costs, and the uncertainty over the performance of available abatement technologies. Finally, this paper constitutes what we believe to be a new development of search theory by using it in envi-

$\overline{4}$ While Perino and Requate (2012) consider a continuum of firms, they assume the presence of only two technologies, so uncertainty of future technology does not play a significant role in their results as it does in ours. 
ronmental economics, and matching it with a particularly compelling real-world example of oil sands tailings, discussed below.Search theory has been applied to a variety of issues since the pioneering work of Stigler (1961) and McCall (1970). In addition to the study of wages and unemployment, applications of search theory have extended to the study of marriage markets, monetary economics, and information theory. Recently, search theory has also made advances in relatively new areas, like financial economics (Moscarini and Wright, 2010).

The analysis in this paper has important policy implications for the environmental regulation within and beyond our chosen example of the Alberta oil sands. We look at environmental policy instrument choice, in the presence of heterogeneous production technologies, high fixed costs of adoption, and uncertainty regarding the choice of abatement options, may impact future emissions and total costs. These conditions are not unique to our example - they would also be present in industries such as petroleum refining and power generation, for example. The results from our model suggest that the Alberta government, in adopting a regulatory standard as opposed to a price-based mechanism, may have reduced the potential for new technologies to be discovered and adopted. As a result, it is likely that the policy choices made in Alberta have decreased the expected future rate of tailings abatement. However, it is not possible for us to say whether these choices have likely increased the expected total compliance costs associated with abatement or the likelihood that firms could be more profitable with new tailings management technology.

The remainder of our paper proceeds as follows. In Section 2, we introduce our motivating example from Alberta's oil sands. Section 3 develops the search model for abatement technologies by firms, and characterize their abatement, search, and adoption decisions under an emissions tax regime. In section 4, we consider firms' decisions under a tradable permit market and an emissions standard. Section 5 discusses the conditions under which the Porter Hypothesis might hold under the alternative regulatory mechanisms we consider. Section 6 concludes the paper. 


\section{Oil sands tailings}

The problem we have in mind is well-illustrated by the abatement decisions currently being made by firms mining the oil sands in Alberta. Oil sands mining generates significant quantities of harmful by-products, and one of these is fluid tails, a mixture of water, clay, sand, residual hydrocarbons, and chemicals. These tailings were initially expected to settle over time when stored in large tailings ponds, however that has not proven to be the case. Instead, the tailings have been found to de-water to a point, but not sufficiently as to allow the land to be reclaimed. Current estimates suggest that it may take 30 years or more for this mixture to settle and solidify. ${ }^{5}$ As of 2010, the most recent comprehensive data point available, tailings ponds in Alberta covered $176 \mathrm{~km}^{2}$ (43, 500 acres) and contained over 830 million $\mathrm{m}^{3}$ (219 billion gallons) of tailings (Government of Alberta, 2013). To put this in perspective, Syncrude's Southwest Sand Storage (SWSS) Facility which encloses a tailings pond is among the largest dams in the world, outsized only by China's Three Gorges dam. ${ }^{6}$ Management of these tailings ponds, including the maintenance of dykes and seepage containment systems represents a significant cost to the companies operating in the oil sands, but these remained the preferred response to a regulatory directive which forbids the discharge of any process-affected water or mine-site effluent into the local watershed.

In February of 2009, in response to the growing volume of tailings and to an incident in which over 1500 ducks perished after landing in one of the ponds, the Alberta Government's Energy Resources Conservation Board introduced Directive 074, Tailings Performance Criteria and Requirements for Oilsands Mining Schemes, which would regulate the deposition rate into tailings ponds and force companies to accelerate the process of separating water out of mature tailings.

In response both to the regulation and to the spiraling costs of managing increasing volumes of tailings on mining sites, multiple abatement technologies have emerged. Some of these technologies focus on direct de-watering and reclamation of tailings, while others (not discussed here) focus on long-term, safe storage of mature tailings. Abatement

$\overline{5}$ For detailed information on the abatement options being considered by the oil sands industry, see http://www.oilsandstoday.ca/topics/Tailings/Pages/default.aspx.

6 See for example, http://h2oildoc.com/home/the-tailing-ponds. 
technologies generally fit into at least four categories: centrifuge approaches, composite tailings, $\mathrm{CO}_{2}$ injection, and surface (or thin-lift) drying. Each of these approaches have different characteristics, and significant uncertainty exists with respect to each technology's long-run performance. Centrifuge approaches, as adopted by the Syncrude consortium, rely on large physical plants which mechanically separate the water from the mature tailings. Composite tailings, also used by Syncrude as well as by Shell's Albian Sands operation, involves adding gypsum and sand to the tailings to speed up the naturally slow consolidation process and provide a surface which can be reclaimed (Syncrude, 2012). $\mathrm{CO}_{2}$ injection, used by Canadian Natural Resources Limited, is similar to consolidated tailings as the $\mathrm{CO}_{2}$ is expected to speed the water separation and thus consolidation process. Surface drying, used by Suncor, combines the addition of a polymer to the tailings, which aids in water separation, with spreading the combined mixture thinly across a broad surface area to speed drying and prepare a reclaimable landscape.

In adopting each of these technologies, firms had to make large investment decisions under significant uncertainty. For example, implementing Suncor's surface drying process, which they refer to as Tailings Reduction Operations, or TRO, required over $\$ 1$ billion in investment in both new infrastructure and to re-align existing processes to integrate with TRO (Suncor, 2013). Syncrude's centrifuge project is proceeding in two stages an initial commercial scale plant which began operating in 2012, and a full-scale, $\$ 1.9$ billion facility to open in 2015 (Syncrude, 2012). Neither of these technologies have been applied in similar settings before, and there remains significant uncertainty with respect to long-run performance and ability to comply with the current regulation (Syncrude, 2013, Government of Alberta, 2013). The thrust of our paper is to examine this investment decision and to characterize the incentives for a firm which faces impending regulation and significant uncertainty with respect to the eventual performance of abatement technology.

The stylized facts from the oilsands industry match important aspects of our model developed below. First, the existence of a continuum of abatement technologies, both ex ante and ex post, results from frictions and uncertainties in the market. In the oil sands industry case, even if a technology appears to be performing well at a competitor's facility, there will be significant costs to deploying that technology as well as uncertainty as to its performance in the specific conditions of the firm in question. Further, prior to the adoption of regulation, firms accelerated adoption of new technologies, and began a col- 


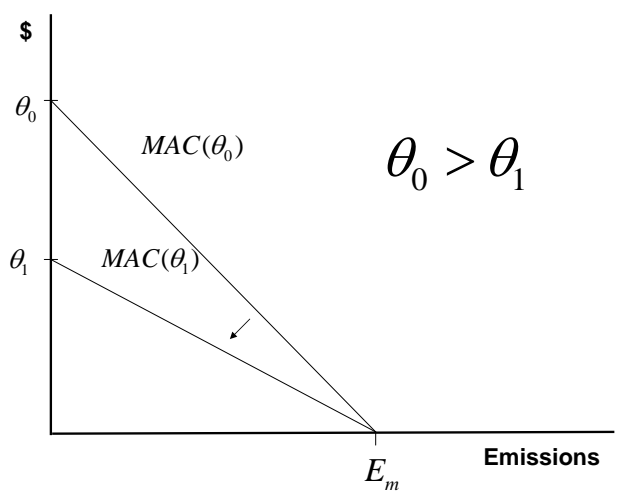

Fig. 1. Marginal Abatement Cost Curves

laborative effort known as the Canadian Oil Sands Innovation Alliance (COSIA) in 2012 to share information on the performance of these new technologies - something which we believe reflects the degree to which this information is not commonly known even after the technology is deployed by one firm. In our model, reducing uncertainty over potential abatement costs with new technology would be a public good, and so the creation of COSIA is consistent with our results. Finally, at least one firm, Suncor, has suggested that its deployment of tailings mitigation technology known as Tailings Reduction Operations may reduce total costs of tailings management in the long term, while also allowing the firm to meet more stringent regulation. Were that to prove correct, it would represent a case of the strong version of the Porter Hypothesis as suggested by our results.

\section{$3 \quad$ Model and Preliminaries}

We consider a single polluting firm search model of abatement technology. Assume there is a continuum of available abatement technologies that differ according to their cost of abatement. These abatement technologies are indexed by efficiency parameter $\theta>0$, which is distributed between $\underline{\theta}$ and $\bar{\theta}$ (with $0<\underline{\theta}<\bar{\theta}<\infty$ ) according to cumulative density function $F(\theta)$ and associated probability density function $f(\theta)$. Let the marginal abatement cost function be $M A C=\theta-\frac{\theta}{E_{m}} E$, where $E$ is the level of emissions, and $E_{m}$ is the maximum emissions level in the absence of abatement. ${ }^{7}$ A smaller value of $\theta$ implies

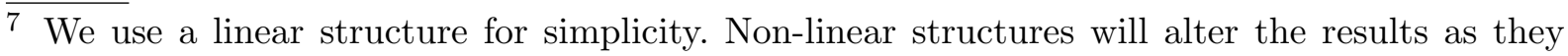
change the relationship between marginal and average costs of abatement. We discuss, where relevant, how convex or concave marginal abatement cost functions would affect our results. 


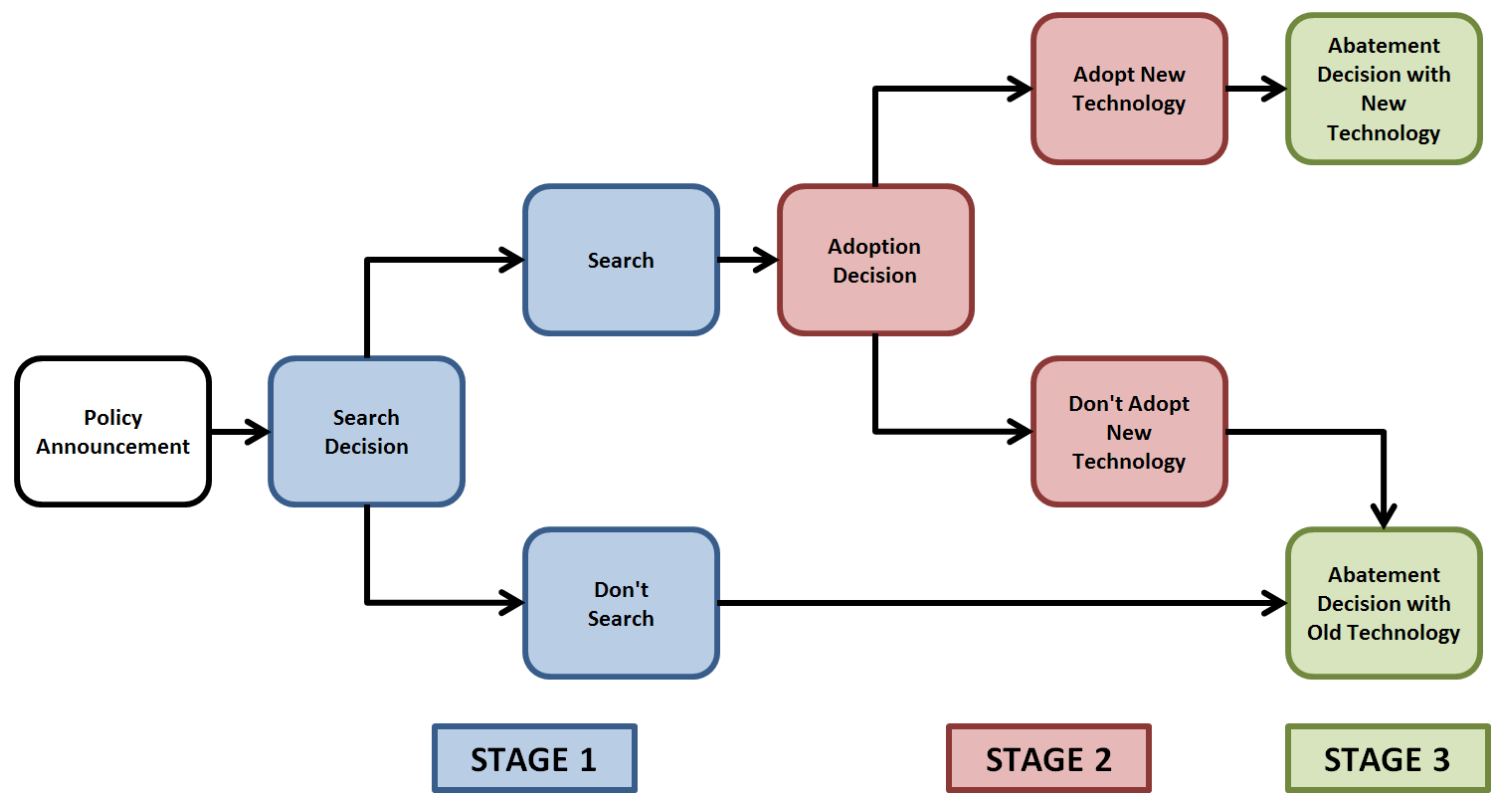

Fig. 2. Our 3-stage game

a more efficient abatement technology and translates to a counterclockwise rotation of $M A C$ through $E_{m}$ (see Figure 1). We implicitly assume that the marginal cost of the first unit of abatement activity is zero, i.e. $M A C=0$ when $E=E_{m}$. Our model is admittedly simplified, but this structure allows us to derive analytic solutions or comparisons not possible with a more complex model.

Given an initial technology endowment, the polluting firm faces a three stage decision game as shown in Figure 2. First, the firm can search for a more efficient abatement technology. The firm knows the distribution of the efficiency of abatement technologies that are available, $f(\theta)$, but it cannot choose a particular technology with knowledge of $\theta$ ex ante. By paying a fixed search $\operatorname{cost} C_{s}$, the firm may acquire a draw from the distribution of new technologies for which it will possess perfect information - this would be analogous to a firm completing the front-end engineering and design (FEED) for implementing a new technology in their plant. The firm must then decide whether to adopt the technology, at known fixed $\operatorname{cost} C_{a}$, or to retain their existing technology. ${ }^{8}$ Finally, the firm makes its abatement decision, conditional on technology.

$\overline{8}$ We do not decompose the adoption costs as done in Biglaiser and Horowitz (1995). If adoption costs were a function of the efficiency of the technology, due to the price of a license from the innovator, our results would be altered. Adoption costs are also likely uncertain prior to the FEED analysis we cite above, but this is beyond the scope of our analysis. 
Below, we solve the 3-stage game recursively for the emissions tax case, and then report in the next section on differences for the emissions standard and the cap-and-trade case.

\subsection{Abatement decision}

Solving the game recursively, we need to obtain first the abatement decision of the firm conditional on efficiency parameter $\theta$. For any emissions tax, $t$, the polluting firm solves

$$
M A C=\theta-\frac{\theta}{E_{m}} E=t
$$

which gives rise to the following expression for the equilibrium emissions level

$$
E(\theta, t)=(\theta-t) \frac{E_{m}}{\theta} .
$$

Equilibrium emissions will be greater than zero whenever $\theta>t$. Emissions abatement will be

$$
A(\theta, t)=(t) \frac{E_{m}}{\theta}
$$

The corresponding total costs of pollution control, under emissions tax $t$ with technology $\theta$ is then given by:

$$
C(t, \theta)=t E(\theta, t)+\int_{E(\theta, t)}^{E_{m}} M A C(\tilde{E}) d \tilde{E}=t E_{m}-\frac{t^{2} E_{m}}{2 \theta} .
$$

At the third stage of the game, $\theta$ is pre-determined as a result of the search and adoption decisions in the previous stages, which we explore below.

\subsection{Technology adoption decision}

In the second stage, the polluting firm decides whether to pay a fixed cost $C_{a}$ in order to adopt the technology drawn in the first stage which we denote as $\theta$. For most abatement technologies, these costs would likely be larger than the search costs by one or more orders of magnitude. For example, in adopting its solution to oil sands tailings management, Syncrude developed a commercial-scale centrifuge plant at a capital cost of $\$ 1.9$ billion, having previously demonstrated the technology at a much smaller pilot facility (Syncrude, 2012). Our model would consider the former an adoption cost, while the latter would be 
part of the search cost. If the polluter does not choose to pay this adoption cost, it will maintain its original technology, which we denote by $\theta_{0}$.

The adoption decision will be determined based on the total costs of pollution control that the firm incurs with the new and old technology choices - it will adopt the drawn technology if $C(t, \theta)+C_{a} \leq C\left(t, \theta_{0}\right)$. As the polluting firm possesses full information about the efficiency of the drawn technology after the search stage, its optimal adoption strategy consists of choosing a reservation technology $\widetilde{\theta}<\theta_{0}$, which exactly satisfies the adoption decision above. This condition is given by:

$$
t E_{m}-\frac{t^{2} E_{m}}{2 \theta_{0}}=t E_{m}-\frac{t^{2} E_{m}}{2 \theta}+C_{a}
$$

and the corresponding reservation technology efficiency becomes

$$
\tilde{\theta}=\frac{t^{2} \theta_{0} E_{m}}{t^{2} E_{m}+2 \theta_{0} C_{a}}
$$

Proposition 1: The reservation technology $(\widetilde{\theta})$ increases (i.e. the firm is willing to pay to adopt a less-efficient technology) with current technology $\left(\theta_{0}\right)$, the stringency of the emission tax $(t)$, and the emissions level in the absence of abatement $\left(E_{m}\right)$, and decreases in the cost of adoption $\left(C_{a}\right)$.

The results can be explained as follows:

(1) The more costly is the current technology, the higher is the technology cost at which you can pay off an investment in adoption. We can see this in the derivative, $\frac{d \widetilde{\theta}}{d \theta_{0}}=$ $\frac{t^{4} E_{m}^{2}}{\left(t^{2} E_{m}+2 \theta_{0} C_{a}\right)^{2}}$, where both numerator and denominator are positive.

(2) The higher is the emissions tax, the higher is the technology cost at which you can pay off the investment in adoption, since $\frac{d \widetilde{\theta}}{d t}=\frac{4 t \theta_{0}^{2} E_{m} C_{a}}{\left(t^{2} E_{m}+2 \theta_{0} C_{a}\right)^{2}}>0$.

(3) The higher are unabated emissions, or flatter is the marginal abatement cost curve, the higher is the technology cost at which you can pay off the investment in technology adoption, since $\frac{d \widetilde{\theta}}{d E_{m}}=\frac{2 t^{2} \theta_{0}^{2} C_{a}}{\left(t^{2} E_{m}+2 \theta_{0} C_{a}\right)^{2}}>0$.

(4) The higher are adoption costs, the better the new technology must be to justify adoption since $\frac{d \widetilde{\theta}}{d C_{a}}=-\frac{2 t^{2} \theta_{0}^{2} E_{m}}{\left(t^{2} E_{m}+2 \theta_{0} C_{a}\right)^{2}}<0$.

The potential for a new technology to be adopted will affect the search decision, in the 
1st stage of our game, discussed below.

\subsection{Technology search decision}

In the search stage, the polluting firm decides whether to pay a fixed cost, $C_{s}$, in order to search for a more efficient abatement technology. These costs would include development of engineering estimates of performance, as well as bench- and pilot-scale tests. ${ }^{9}$ The firm will only search for a new technology if the total costs of pollution control without search $C\left(\theta_{0}, t\right)$ are greater than the search costs and the expected total costs of pollution control with a new technology in place by a sufficient-enough margin to cover search and adoption costs. The firm knows that it will only adopt a technology with $\theta<\widetilde{\theta}$, as derived in state two of the game. Given the distribution of potential technologies $F(\theta)$, we can write the following condition for the search decision:

$$
C_{s} \leq F(\widetilde{\theta})\left[C\left(\theta_{0}, t\right)-E[C(\theta, t) \mid \theta<\tilde{\theta}]-C_{a}\right]
$$

where $F(\widetilde{\theta})$ and $1-F(\widetilde{\theta})$ are respectively the probability of adopting and rejected the drawn technology, and the expectation is over the conditional expected costs of abatement given the search process and the adoption decision. We can determine the expected value of future abatement costs, for technology draws of $\theta<\widetilde{\theta}$, as follows:

$$
E[C(\theta, t) \mid \theta \leq \widetilde{\theta}]=t E_{m}-\frac{t^{2} E_{m}}{2} \int_{\underline{\theta}}^{\widetilde{\theta}} \frac{1}{\theta} f(\theta) d \theta
$$

From (3.4) and (3.8) we can rewrite the condition for search in (3.7) as follows:

$$
C_{s} \leq F(\widetilde{\theta})\left[C_{a}+\frac{t^{2} E_{m}}{2 \theta_{0}}-\int_{\underline{\theta}}^{\widetilde{\theta}} \frac{t^{2} E_{m}}{2 \theta} f(\theta) d \theta\right] .
$$

From (3.9), we can derive the expression of the reservation cost of search, denoted as $\bar{C}_{s}$, that leaves the polluter indifferent between searching for a more efficient technology and sticking to its original technology:

$$
\bar{C}_{s}=\left[\frac{t^{2} E_{m}}{2}\left(\int_{\underline{\theta}}^{\widetilde{\theta}} \frac{1}{\theta} f(\theta) d \theta-\frac{1}{\theta_{0}}\right)-C_{a}\right] \int_{\underline{\theta}}^{\widetilde{\theta}} f(\theta) d \theta .
$$

$\overline{9}$ Bench-scale refers to laboratory experiments, while pilot-scale would be a larger but still not commercial-scale implementation. For oil sands tailings, a tailings plant which processed a fraction of total tailings generated on a site might be considered pilot-scale. 
The polluting firm searches for a new technology when the cost of search is less than or equal to $\bar{C}_{s}$, i.e. when the expected benefits, in terms of pollution control cost savings stemming from the use of a more cost efficient technology, are high enough to compensate for the expected economic costs of search and potential adoption of the new technology.

The reservation cost of search is increasing in the current abatement cost, as $\frac{d \bar{C}_{s}}{d \theta_{0}}>0$. As a result, firms are more likely to remain with their current technology when search costs are high or when the potential for improvement is relatively low. Policy also drives search decisions in intuitive ways - the reservation search cost is increasing in the tax level, as $\frac{d \bar{C}_{s}}{d t}>0$. There is also an important interaction between adoption and search costs. The higher are adoption costs, the lower is the reservation search cost, since $\frac{d \bar{C}_{s}}{d C_{a}}=-F(\widetilde{\theta})<0$. In other words, all else equal, the firm is willing to spend less on search if adoption is more expensive.

In the oil sands, the main companies have recently formed a consortium known as the Canadian Oil Sands Innovation Alliance (COSIA) for the purposes of sharing information about new, environmental technologies (COSIA, 2014). In the context of our model, COSIA would be a means both of reducing search cost and of reducing the variance in potential technology draws for a given company, as they can more effectively target their efforts given the experience of other companies in the same area.

\section{Alternative Policy Instruments}

This section analyzes the equilibrium outcomes under a tradable permit system and a standard, where each policy instrument has a common ex ante shadow value, and so would produce the same environmental outcome in the absence of the search and adoption decisions.

\subsection{Tradable emissions permits}

An emissions permit regime represents a hybrid between the standard discussed below and the tax in terms of the implications for search. The initial compliance costs are lower than or equal to the tax, and may even be negative. Here, we assume that the individual 
firm is of sufficiently small size to not influence the price of emissions in the trading regime through its abatement decisions.

Let the initial allocation of emissions permits be represented by $E_{0}$, and let the equilibrium permit price be given by $p$. Emissions are $E(\theta, p)=(\theta-p) \frac{E_{m}}{\theta}$, and the total costs of pollution control are as follows:

$$
C(\theta, p)=p E-p E_{0}+\int_{E(\theta, p)}^{E_{m}} M A C(\tilde{E}) d \tilde{E}=p\left(E_{m}-E_{0}\right)-\frac{p^{2} E_{m}}{2 \theta} .
$$

As such, as long as permit allocations are weakly positive, the abatement costs will always be weakly lower than abatement costs under the tax. However, since the allocation of emissions permits does not depend on emissions, the condition for technology adoption, $\widetilde{\theta}_{p}$ is the same as that for an emissions tax, since the firm can capitalize on any permit sales or reduction in permit purchases resulting from increased abatement. The reservation technology is given by:

$$
\widetilde{\theta}_{p}=\frac{\theta_{0} E_{m} p^{2}}{E_{m} p^{2}+2 \theta_{0} C_{a}}
$$

Similarly, the search decision is determined by the ability of the firm to compensate for search costs through lowered future abatement costs as well as the change in net permit revenue. A firm facing a tradeable permit regime with initial permit allocation $E_{0}$ and trading price $p$ will search for a new technology if the search cost is such that the expected total abatement cost savings are greater than the search and conditional adoption costs. The setup is similar to that for the emissions tax, shown in (3.7), with the exception of the permit allocations:

$$
C_{s} \leq C\left(\theta_{0}, p\right)-\left[1-F\left(\tilde{\theta}_{p}\right)\right] C\left(\theta_{0}, p\right)-F\left(\tilde{\theta}_{p}\right) E\left[C(\theta, p) \mid \theta<\widetilde{\theta}_{p}\right]-F\left(\widetilde{\theta}_{p}\right) C_{a} .
$$

Given that the expression in (4.2) is equivalent to that in (3.6), and the adoption costs are common, the only discrepancies between (4.3) and (3.7) are the total abatement costs, which contain an extra term, $-p E_{0}$ in the case of the tradeable permits. However, since the permit allocation and value do not depend on the outcome of the search and adoption process, by assumption, this extra term will drop out of the search condition, and so we can define the search condition for permits as: 


$$
C_{s} \leq-F\left(\widetilde{\theta_{p}}\right)\left[C_{a}+\frac{p^{2} E_{m}}{2 \theta_{0}}-\int_{\underline{\theta}}^{\widetilde{\theta_{p}}} \frac{p^{2} E_{m}}{2 \theta} f(\theta) d \theta\right]
$$

Our results above would change if the permit endowment were to be a function of the emissions within a period under, for example, an emissions-intensity or output-basedallocation regime. Similarly, in a dynamic context where firms' future endowments depend on today's emissions, the results would be different as there would be less incentive to reduce emissions in any given period.

\subsection{Emissions standard}

Emissions standards, while simple in appearance, present a meaningfully different problem for the firm. The standard restricts emissions to $E_{s}=\left(\theta_{0}-s\right) \frac{E_{m}}{\theta_{0}}$, where $s$ is the shadow value. However, unlike the tax, a change in $\theta$ due to search will reduce the shadow value of the standard rather than reducing the endogenous level of emissions. For comparability, we set $s=t$. Under the standard, the total costs of pollution control are initially lower than with the tax, because there is no transfer payment. The total costs are as follows:

$$
C\left(E_{s}, \theta\right)=\int_{E(\theta, t)}^{E_{m}} M A C(\tilde{E}) d \tilde{E}=\frac{\theta\left(E_{m}-E_{s}\right)^{2}}{2 E_{m}}=\frac{E_{m} s^{2}}{2 \theta_{0}} .
$$

A new technology, $\theta_{1}$, would reduce the costs of meeting the standard $E_{s}$ by:

$$
C\left(E_{s}, \theta_{0}\right)-C\left(E_{s}, \theta_{1}\right)=\left(\frac{\theta_{0}-\theta_{1}}{\theta_{0}}\right)\left(\frac{E_{m} s^{2}}{2 \theta_{0}}\right) .
$$

As such, a new technology will only be adopted if the drawn technology index is less than $\tilde{\theta}_{s t}$ defined as follows:

$$
\tilde{\theta}_{s t}=\theta_{0}-\frac{2 C_{a} \theta_{0}^{2}}{s^{2} E_{m}}
$$

We can derive the search condition, which relies on the likelihood of drawing a technology sufficient for adoption and for which the cost savings, net of adoption costs, are sufficient to justify the search costs. The condition for searching dictates that the firm will search 
as long as the costs are less than $\bar{C}_{s, s t}$ defined as:

$$
\bar{C}_{s, s t}=\left[\frac{s^{2} E_{m}}{2 \theta_{0}}\left(1-\int_{\underline{\theta}}^{\widetilde{\theta}_{s t}} \frac{\theta}{\theta_{0}} f(\theta) d \theta\right)-C_{a}\right] \int_{\underline{\theta}}^{\widetilde{\theta}_{s t}} f(\theta) d \theta .
$$

Proposition 2: With respect to search and adoption, a tradeable permit regime is equivalent to a tax as long as the permit allocation does not depend on emissions. Under an emissions standard with an ex ante shadow value $s$, the reservation technology for adoption is more efficient, the reservation cost of search lower and expected emissions higher than with a tax or a tradeable permit regime with $t=p=s$; the magnitude of expected future abatement costs may be higher or lower than with a tax or a tradeable permit regime.

We can now describe these results as follows.

(1) Firms have less incentive to search for and to adopt new technologies with a standard than with a tax or a tradeable emissions permit system, as long as the tax rate and the shadow value of the standard are equivalent ex ante. From (3.10) and (4.8), we can show that

$$
\begin{aligned}
\bar{C}_{s}-\bar{C}_{s, s t}=t^{2} E_{m} & {\left[\int_{\underline{\theta}}^{\widetilde{\widetilde{\theta}}} \frac{1}{2 \theta} f(\theta) d \theta-\frac{1}{\theta_{0}}+\int_{\underline{\theta}}^{\widetilde{\theta}_{s t}} \frac{\theta}{2 \theta_{0}^{2}} f(\theta) d \theta\right] \int_{\underline{\theta}}^{\widetilde{\theta}_{s t}} f(\theta) d \theta } \\
+ & {\left[\frac{t^{2} E_{m}}{2}\left(\int_{\underline{\theta}}^{\widetilde{\theta}} \frac{1}{\theta} f(\theta) d \theta-\frac{1}{\theta_{0}}\right)-C_{a}\right] \int_{\widetilde{\theta}_{s t}}^{\widetilde{\theta}^{2}} f(\theta) d \theta>0 . }
\end{aligned}
$$

From (3.6) and (4.7), we obtain $\widetilde{\theta}_{s t}-\widetilde{\theta}=-\frac{4 \theta_{0}\left(\theta_{0} C_{a}\right)^{2}}{E_{m} t^{2}\left(E_{m} t^{2}+2 \theta_{0} C_{a}\right)}<0$.

(2) Expected future emissions under the standard are greater than those under the tax or the permit system. This follows directly from the fact that, under the standard, the emissions remain fixed at $E=\frac{\left(\theta_{0}-t_{0}\right) E_{m}}{\theta_{0}}$ even with a change in $\theta$ due to search and adoption, while the emissions under the tax and the permit system will be reduced through endogenous increases in abatement.

(3) Expected cost savings from search and adoption are larger under the tax or the tradeable permit regime than under the standard, but there is an ambiguous relationship between expected future compliance costs under the various policy options depending on the initial values of theta. Under the standard, the cost savings associated with any particular draw of $\theta_{1}$ given initial condition $\theta_{0}$ and shadow value $t$ are $\left(\frac{\theta_{0}-\theta_{1}}{\theta_{0}}\right)\left(\frac{t^{2} E_{m}}{2 \theta_{0}}\right)$. The analogous condition for a tax (or tradeable permit regime) 
is $\left(\frac{\theta_{0}-\theta_{1}}{\theta_{1}}\right)\left(\frac{t^{2} E_{m}}{2 \theta_{0}}\right)$. As such, for any adopted $\theta_{1}$, the savings would be larger under the tax. The fact that higher gains are possible for any given draw of $\theta$ implies, as shown in comparing (4.7) to (3.6), that the firm will adopt a larger suite of technologies if drawn with the tax (or the permit regime) in place than under the standard. These higher expected gains imply that, all else equal, the firm will search for a wider range of initial $\theta$ values. As such, for any initial $\theta$, the expected savings in future compliance costs from search and adoption are higher with the tax than the standard.

\section{Abatement Technology Search and the Porter Hy- pothesis}

Having characterized the search and adoption behavior of firms given a particular technology endowment and policy parameters, we can examine how these behaviors may translate into support for the Porter Hypothesis. Recall that the Porter hypothesis suggests that more stringent but well-designed environment regulations may benefit firms by stimulating innovation, which may more than offset the costs of complying with these regulations (Porter and van der Linde, 1995). Our framework admits a case where, due to search and adoption costs and uncertainties, a firm would have a more costly abatement technology than would have been the case with a deterministic innovation environment. As such, it is immediately more plausible that an increase in regulatory stringency, by increasing the incentives to search, could lead to significant improvements in technology which overcome the increased stringency of the policy in question. For any change in policy, we can identify the expected improvements in the total abatement costs from search and show the likelihood that a firm would see lower total abatement costs, and therefore higher profitability, under a new, more stringent emissions policy.

We consider an increase in the stringency of environmental policy, from one with a shadow price of $t_{0}$ to a shadow price of $t_{1}$. In the case of tradeable permits, we also examine the impacts of a change in permit allocation. We consider a firm with initial technology level $\theta_{0}$ that may search for and potentially adopt a new and more efficient technology drawn from a distribution, $f(\theta)$, and examine the expected change in its total abatement costs under the different policy mechanisms considered above. 


\subsection{Emissions Taxes}

Under an emissions tax, the initial abatement costs for the firm would be given as in (3.4) above, under emissions tax $t_{0}$ and with technology $\theta_{0}$ by:

$$
C\left(t_{0}, \theta_{0}\right)=t_{0} E_{m}-\frac{t_{0}^{2} E_{m}}{2 \theta_{0}}
$$

When the policy stringency is increased, there are two possibilities: either the firm will choose to search, or will not choose to search, given the values of $t_{1}$ and $\theta_{0}$. Using the solution to the three-stage game derived above, we can develop specific conditions in which the Porter Hypothesis will be expected to hold.

First, it must be the case that a feasible draw exists from the distribution of potential technologies which would allow total compliance costs to decline with the increases in stringency. This condition reduces to a critical value of $\hat{\theta}$ such that it's possible to observe the strong version of the Porter Hypothesis so long as:

$$
\hat{\theta}=\frac{t_{1}^{2} E_{m}}{2\left(t_{1}-t_{0}+\frac{t_{0}^{2}}{2 \theta_{0}}\right) E_{m}+2\left(C_{s}+C_{a}\right)}>\underline{\theta} .
$$

For the case to be interesting beyond a one-shot game, we would want to consider cases where the change in policy makes search and potential adoption optimal where it was not before. For this to be true, it first must be the case that:

$$
F(\widetilde{\theta})\left(\frac{t_{0}^{2} E_{m}}{2} \int_{\underline{\theta}}^{\widetilde{\theta}} \frac{1}{\theta} f(\theta) d \theta-\frac{1}{\theta_{0}}-C_{a}\right)-C_{s}<0,
$$

where $\widetilde{\theta}$ is defined for tax rate $t_{0}$ and technology $\theta_{0}$ as given in (3.6). It must also be the case, for $\widetilde{\theta}$ defined for tax rate $t_{1}$ and technology $\theta_{0}$, that:

$$
F(\widetilde{\theta})\left[\frac{t_{1}^{2} E_{m}}{2}\left(\int_{\underline{\theta}}^{\widetilde{\theta}} \frac{1}{\theta} f(\theta) d \theta-\frac{1}{\theta_{0}}\right)-C_{a}\right]-C_{s}>0 .
$$

As long as $\theta_{0}$ satisfies conditions (5.2), (5.3), and (5.4), then the Porter hypothesis can be realized in response to the change in policy from reasonable initial conditions. It is 
possible, but not a necessary condition for its occurrence, that the strong version of the Porter Hypothesis will be the expected outcome. This will be the case if:

$F(\widetilde{\theta})\left(\int_{\underline{\theta}}^{\widetilde{\theta}} t_{1} E_{m}-\frac{t_{1}^{2} E_{m}}{2 \theta} f(\theta) d \theta+C_{a}\right)+(1-F(\widetilde{\theta}))\left(t_{1} E_{m}-\frac{t_{1}^{2} E_{m}}{2 \theta_{0}}\right)+C_{s}<t_{0} E_{m}-\frac{t_{0}^{2} E_{m}}{2 \theta_{0}}$.

On the left-hand side of (5.5), the first two terms represent the expected total compliance costs in the event that a search is successful and in the event that a search does not yield an adoptable technology respectively. These terms are weighted by the probability of drawing a technology sufficient for adoption, where $\widetilde{\theta}$ is defined as in (3.6). If these costs, plus the cost of searching, are less than compliance costs before the change in regulation, shown on the right hand side, the expected outcome of the policy change would be the strong version of the Porter Hypothesis.

The presence of search and adoption costs makes it possible for the Porter Hypothesis to occur as the product of decisions made under rational expectations, even in a dynamic version of the one-shot game we examine. Without search and adoption costs, firms would innovate and existing technology would be less costly as a result. Search and adoption costs allow for dispersion in ex ante technology, as well as ex post technology. As a result, in order to see the Porter Hypothesis play out in practice, you would need search and adoption costs which are sufficiently high that firms are using a technology which is significantly more costly than they would use if search and adoption were costless.

\subsection{Tradeable Permits}

Moving from a tax to a tradeable emissions permit system increases the likelihood of observing the Porter Hypothesis under certain conditions, since the total compliance costs will be weakly lower than with a tax, but the potential gains and thus the incentives for search are identical.

The critical value of $\hat{\theta}_{p}$ such that it is possible to observe the strong version of the Porter Hypothesis under a tradeable emissions permit is given by:

$$
\hat{\theta}_{p}=\frac{p_{1}^{2} E_{m}}{2\left(p_{1}-p_{0}+\frac{t_{0}^{2}}{2 \theta_{0}}\right) E_{m}+2\left(C_{s}+C_{a}\right)-2\left(p_{1}-p_{0}\right) E_{0}}>\underline{\theta} .
$$


This condition differs from the tax due to the presence of the endowments both before and after the policy change on the denominator. As such, for any policy stringency, as long as $p_{1} E_{1}-p_{0} E_{0}>0$, it will be the case that $\hat{\theta}_{p}>\hat{\theta}$. Under an emissions permit regime, conditions (5.3) and (5.4) still hold as with the tax. However, under a tradeable emissions permit regime, the strong version of the Porter Hypothesis (that a firm may be more profitable after an increase in the stringency of an environmental regulation) will hold in expectation if:

$$
\begin{array}{r}
F\left(\widetilde{\theta_{p}}\right)\left(\int_{\underline{\theta}}^{\widetilde{\theta_{p}}} p_{1} E_{m}-\frac{p_{1}^{2} E_{m}}{2 \theta} f(\theta) d \theta+C_{a}\right)+\left(1-F\left(\widetilde{\theta_{p}}\right)\right)\left(p_{1} E_{m}-\frac{p_{1}^{2} E_{m}}{2 \theta_{0}}\right)+ \\
+C_{s}-p_{1} E_{0}<p_{0} E_{m}-\frac{p_{0}^{2} E_{m}}{2 \theta_{0}}-p_{0} E_{0} .
\end{array}
$$

As long as permit allocations do not change, the likelihood of a result consistent with the Porter Hypothesis holding under tradeable emissions permits will be higher than with a tax. If both the price and allocation of permits change, the strong version of the Porter Hypothesis will hold in expectation if:

$$
\begin{array}{r}
F\left(\widetilde{\theta_{p}}\right)\left(\int_{\underline{\theta}}^{\widetilde{\theta_{p}}} p_{1} E_{m}-\frac{p_{1}^{2} E_{m}}{2 \theta} f(\theta) d \theta+C_{a}\right)+\left(1-F\left(\widetilde{\theta_{p}}\right)\right)\left(p_{1} E_{m}-\frac{p_{1}^{2} E_{m}}{2 \theta_{0}}\right)+ \\
+C_{s}-p_{1} E_{1}<p_{0} E_{m}-\frac{p_{0}^{2} E_{m}}{2 \theta_{0}}-p_{0} E_{0} .
\end{array}
$$

In this last case, we cannot sign the effect relative to the carbon tax. However, if the ex post value of allocated permits increases $\left(p_{1} E_{1}>p_{0} E_{0}\right)$ then the expected increase in compliance costs will be smaller with a tradeable permit system than with a tax, and so it is, again, more likely to be consistent with the Porter Hypothesis than is a comparable change in an emissions tax.

\subsection{Emissions Standard}

As in the section above, emissions standards present a different problem from the emissions tax because the shadow value of the standard changes with innovation. We can write out similar conditions for search incentives before and after changes in the emissions standard's ex ante shadow value from $s_{0}$ to $s_{1}$ as follows.

As with the tax, we can define the conditions under which a feasible value of $\hat{\theta}_{\text {st }}$ exists 
such that it is possible to observe the strong version of the Porter Hypothesis - this will occur so long as:

$$
\hat{\theta}_{s t}=\frac{s_{0}^{2} E_{m} \theta_{0}-2 \theta_{0}^{2}\left(C_{s}+C_{a}\right)}{s_{1}^{2} E_{m}}>\underline{\theta} .
$$

For non-trivial cases where the change in policy makes search and potential adoption optimal where it was not before, it first must be the case that:

$$
F\left(\widetilde{\theta}_{s t}\right)\left[\frac{E_{m} s_{0}^{2}}{2 \theta_{0}^{2}}\left(\theta_{0}-\int_{\underline{\theta}}^{\widetilde{\theta}_{s t}} \theta f(\theta) d \theta\right)-C_{a}\right]-C_{s}<0
$$

where $\widetilde{\theta}_{s}$ is defined in this case for shadow value $s_{0}$ and technology $\theta_{0}$ as given in (4.7). When the standard is increased, and $\widetilde{\theta}_{s}$ is defined for shadow value $s_{1}$ and technology $\theta_{0}$, it must also be the case that:

$$
F\left(\widetilde{\theta}_{s t}\right)\left[\frac{E_{m} s_{1}^{2}}{2 \theta_{0}^{2}}\left(\theta_{0}-\int_{\underline{\theta}}^{\widetilde{\theta}_{s t}} \theta f(\theta) d \theta\right)-C_{a}\right]-C_{s}>0 .
$$

If conditions (5.9), (5.10) and (5.11) are satisfied, then the Porter hypothesis can be realized in response to the change in policy. The strong version of the Porter Hypothesis will hold in expectation if:

$$
F\left(\widetilde{\theta_{s}}\right)\left(\int_{\underline{\theta}}^{\widetilde{\theta_{s}}} \frac{\theta E_{m} s_{1}^{2}}{2 \theta_{0}^{2}} f(\theta) d \theta+C_{a}\right)+\left(1-F\left(\widetilde{\theta_{s}}\right)\right)\left(\frac{s_{1}^{2} E_{m}}{2 \theta_{0}}\right)+C_{s}<\frac{s_{0}^{2} E_{m}}{2 \theta_{0}} .
$$

The search and adoption thresholds for an emissions standard are different for an emissions tax or permit regime of comparable stringency, so the firm is less likely to search and, conditional on search, less likely to adopt a new technology, all else equal. As a result, we are less likely to see reductions in cost, and the reductions in cost for a given innovation would be smaller. However, since initial compliance costs are also smaller, the potential remains for a Porter Hypothesis result to be generated from search and adoption of new technology under appropriate conditions.

We cannot say with certainty that a standard is more or less likely than a tax to yield a Porter hypothesis result under a general set of conditions. We can, however, say that larger search and adoption cost create a plausible set of circumstances in which an outcome consistent with the Porter Hypothesis may be sustained for firms with rational expectations 
of future compliance costs under an equilibrium with search. Without search and adoption costs, one could postulate an initial condition in which a firm's abatement technology were very costly, and thus significant gains from innovation would exist, but these initial conditions would not be consistent with a rational expectations equilibrium. Once search costs and adoption costs are added, we would expect to see dispersion in both ex ante and ex post technological states across firms, even in a repeated version of the one-shot game we consider. This dispersion due to frictions in abatement technology adoption presents the possibility of much larger gains from innovation after policy changes than would be possible without the frictions, and thus admit the Porter hypothesis.

The dispersion in technologies, both ex ante and ex post, is consistent with our motivating example of technology search and adoption in the oil sands. The management of tailings containment ponds have been a source of significant cost for oil sands operators. Recent technologies, the adoption of which was accelerated by the Government of Alberta adopting new regulations for tailings inflow in 2009, have changed mine planning significantly. For example, Suncor claims that its new technology for tailings reduction will reduce the number of tailings ponds at its mine site from eight to two, and reduce the expanse of land area by $80 \%$ (Suncor, 2013). This will significantly reduce management costs for containment, so it is certainly possible that the ex post state, after the regulation, will see lower total tailings management costs than the ex ante state.

\section{Concluding remarks}

We use a search model to analyze the economics of abatement technology search and adoption for a polluting firm. We show that a polluting firm has equivalent incentives to adopt a more efficient abatement technology under the emissions tax and permit system and that these are stronger than those present under an equivalently stringent emissions standard. While the tradeable emissions permit system performs as well as the tax in terms of generating innovation, it may be accompanied by lower total compliance costs. We show that this implies that a tradeable emissions permit regime is at least weakly more likely to admit an increase in the profitability of the polluting firm after an increase in the stringency of regulation, the so-called Porter Hypothesis. 
The Alberta oil sands, and specifically the decisions made by firms in the face of policies to reduce the accumulation of mining tailings, provide the example from which we motivate our paper. For this industry, these results are important, but also come with some caveats. The results show that the objectives of the regulator to maximize abatement and promote innovation in the reduction of tailings would be better served by a tax or a tradeable permit regime. However, in terms of the competing objective for the regulator of minimizing total compliance cost, the opportunities offered by tradeable permits in this case are likely limited. Given that the market would be dominated by a small number of very large players, market power in the sale of permits would be a very likely outcome. As such, the regulator will continue to face a tradeoff between a standard as is in place today, with limited incentive for innovation but low compliance cost, and a tax with higher incentives for innovation and higher compliance costs. We cannot, on the basis of our results, argue that one or the other approach would be more likely to yield an ex post outcome consistent with the Porter Hypothesis. Our result suggest that a hybrid policy, perhaps with the government as the default buyer for tailings reductions credits, might yield the best compromise.

There are several potential extensions of our approach. First, we model a single firm search problem, while it would be worthwhile to consider the presence of a polluting industry consisting of more than one firm. In this oligopolistic framework, which would be more consistent with the oil sands production environment in Alberta, it would be interesting to see how the interactions or competition between firms can affect their search and adoption behaviour. Second, using a similar extension, it would be interesting to consider the case where the cost of adopting the new technology is not exogenous. For example, one could think that the cost of adoption depends on the stringency of the regulation or the quality of the technology. Finally, we have considered only partial equilibrium where policies are not set to maximize social welfare. Since we know that optimal policies (taxes and standards) will vary as technology improves, considering endogenous optimal policy in a search framework is likely to provide new and important results. 


\section{References}

[1] Ambec, S., Cohen, M.A., Elgie, S. and P. Lanoie (2013), "The Porter Hypothesis at 20: Can Environmental Regulation Enhance Innovation and Competitiveness?", Review of Environmental Economics and Policy, 7(1): 2-22.

[2] Bramoullé, Y. and L.O. Olson (2005), "Allocation of Pollution Abatement under Learning by Doing", Journal of Public Economics, 89: 1935-1960.

[3] Biglaiser, G. and K.K. Horowitz (1995), "Pollution Regulation and Incentives for Pollution Control Research", Journal of Environmental Economics and Management, 3: 663-684.

[4] Canadian Oil Sands Innovation Alliance (COSIA) (2014), "Tailings", Website: http://www.cosia.ca/initiatives/tailings, Accessed February, 2014.

[5] Fischer, C., Parry, I.W.H., and W.A. Pizzer (2003), "Instrument Choice for Environmental Protection when Technological Innovation is Endogenous", Journal of Environmental Economics and Management, 45: 523-545.

[6] Fischer, C. and T. Sterner (2012), "Climate Policy, Uncertainty, and the Role of Technological Innovation", Journal of Public Economic Theory, 14(2): 285-309.

[7] Jaffe, A., Newell, R.G. and R.N. Stavins (2002), "Environmental Policy and Technological Change", Environmental and Resource Economics, 22: 41-69.

[8] Jaffe, A.B., Newell, R.G. and R.N. Stavins (2003), "Technological Change and the Environment", in The Handbook of Environmental Economics., K.G. Mler and J. Vincent, eds., Amsterdam: North Holland/Elsevier Science.

[9] Jung, C., Krutilla, K. and R. Boyd (1996), "Incentives for Advanced Pollution Abatement Technology at the Industry Level: An Evaluation of Policy Alternatives", Journal of Environmental Economics and Management, 30: 95-111.

[10] Lewis, T.R. (1996), "Protecting the Environment When Costs and Benefits are Privately Known", The RAND Journal of Economics, 27(4): 819-47.

[11] McCall, J.J. (1970), "Economics of Information and Job Search", Quarterly Journal of Economics, 84(1): 113-126.

[12] Milliman, S.R. and R. Prince (1989), "Firm Incentives to Promote Technological Change in Pollution Control", Journal of Environmental Economics and Management, 17: 247-265.

[13] Moscarini, G. and R. Wright (2010), "Introduction to Search Theory and Applications", Journal of Economic Theory, 145: 1319-1324.

[14] Perino, G. and T. Requate (2012), "Does More Stringent Environmental Regulation Induce or Reduce Technology Adoption? When the Rate of Technology Adoption is Inverted Ushaped", Journal of Environmental Economics and Management, 64: 456-467. 
[15] Porter, M.E and C. van der Linde (1995), "Towards a New Conception of the EnvironmentCompetitiveness Relationship", Journal of Economic Perspectives, 9(4): 97-118.

[16] Quirion, P. (2004), "Prices versus Quantities in a Second-Best Setting", Environmental and Resource Economics, 29: 337-359.

[17] Requate, T. and W. Unold (2003), "Environmental Policy Incentives to Adopt Advanced Abatement Technology: Will the True Ranking Please Stand Up", European Economic Review, 47: 125-146.

[18] Requate, T. (2005), "Dynamic Incentives by Environmental Policy Instruments - A Survey", Ecological Economics, 54: 175-195.

[19] Rogerson, R., Shimer, R. and R. Wright (2005), "Search-Theoretic Models of the Labor Market: A Survey", Journal of Economic Literature, 43: 959-988.

[20] Stavins, R.N. (1996), "Correlated Uncertainty and Policy Instrument Choice", Journal of Environmental Economics and Management, 30(2): 218-232.

[21] Stigler, G.J. (1961), "The Economics of Information", Journal of Political Economy, 69(3): 213-225.

[22] Suncor (2013), "Report on Sustainability", Suncor, July 1, 2013.

[23] Syncrude (2012), "Sustainability Report", Syncrude, July 1, 2012.

[24] Weitzman, M.L. (1974), "Prices versus Quantities", Review of Economic Studies, 41(4): 477-491. 